\title{
Right use of Screening Pulse Oximetry test for early detection of Critical Congenital Heart Diseases
}

\author{
A.C. Petropoulos ${ }^{* 1,2}$ MD \\ ${ }^{1}$ Morkezi Klinika \\ ${ }^{2}$ Azerbaijan Medical University, Baku, Azerbaijan.
}

Corresponding author:*Dr Andreas C Petropoulos, andrepetropoulos@gmail.com

\begin{abstract}
Introduction: Preventive medicine is the ideal way in dealing with frequent and fatal diseases. Congenital heart disease (CHD) is responsible for the largest proportion of mortality caused by birth defects in the first year of life. Actual numbers and mortality from CHD is increasing. In the developed world the treatment of CHD has escalating costs for health care systems and private covered patients, while in low-income countries the resources are minimal. Prevention/early detection is urgently needed to tackle the increasing needs.

Aim: To justify why pulse oximetry (pox) is the best available, early detecting postnatal screening test currently. Conclusion: Although CHD's are both frequent and carry a high morbidity and mortality, we still lack a single, easy to apply, non-invasive and low-cost screening test, worldwide. The most advantageous method for minimizing CHD deaths worldwide seems to be currently, the combination of clinical assessment with pox.
\end{abstract}

Keywords: Prevention/Early detection of congenital heart diseases; Critical congenital heart disease; Pulse oximetry screening test for critical congenital heart disease

Abbreviations: CHD: Congenital Heart Disease; pox: Pulse Oximetry; echo-2D: Echocardiography; NT: Nuchal Translucency; c-CHD: Critical-CHD; DA: Ductus Arteriosus; $\mathrm{SpO}_{2}$ : Saturation of Oxygen

Introduction. Hippocrates first stated that "Prevention is better than any cure". The value of this statement - if and when possible - has been tested numerous times and has been adopted as the golden standard of care [1]. CHD's rank among the most common, high morbidity and mortality congenital malformations found [2]. Before echocardiography era, incidence worldwide, ranged from 8-12/1000 live births [3]. This depends on how early and how intensively the diagnosis was made. The best current figure in use is 10-12 per 1000 live births [3]. Caveats apply when calculating the prevalence in neonatal age as some CHD's present in later life (e.g. small Atrial Septal Defects, mild Coarctation of the Aorta, hypertrophic obstructive cardiomyopathies, stenosis or regurgitation from a bicuspid aortic valve.) [4]. As majority of studies come from developed countries, is this incident universal? The Ministry of Health of the People's Republic of China, in 2012, reported a higher prevalence of $1.512 \%$ of CHD in China, with the comment of increasing the number when a national study of all age-all CHD will have been completed [5].
Further, when calculating the world burdens of CHD, the most important fact is not country prevalence itself, but how many children with CHD's, are born per million populations in each country. This, is calculated through the fertility rate of each country. Open sources such as Wikipedia, United Nations reports and the CIA World Factbook, indicate that low income and lower middle-income countries of sub-Saharan Africa, Middle East, Islamic states of the Indian peninsular and Southeast Asia present the higher fertility rates from 4 to 8 children per woman. So, these countries will have more patients and already have less resources to deal with them [3].

Children with CHD have additional morbidity. These, are associated with genetic syndromes (most common Down's syndrome), defects in several other systems, and neuro developmental isuues $[2,4]$. Studies have showed moderate to severe neuro developmental disabilities in over $50 \%$ of children with severe or palliated surgically as neonate's, CHD's. Even in those with less severe anomalies, $25 \%$ will have a degree of cognitive impairment [6]. 
Summarizing, the high incidence of CHD around the world, the significant morbidity and mortality and the expensive, sophisticated and in many forms multidisciplinary treatment (medicine, intervention, surgical) and frequent lifelong followup, characterizes CHD as a major public health condition. On the other hand, as resources to treat CHD both in a matter of Human and finance, are inadequate and seriously mal distributed around the world, these patients are deprived the quality of care needed $[2,3,7]$. This leaves us, with an essential need of a strategy of preventing/ early detecting patients with CHD.

\section{Methods}

Historically, methods used in preventing/early detecting CHD have included embryology, biochemistry, epidemiology, pediatrics, obstetrics, imaging and genetics [2]. Several risk factors are linked with CHDs, such as: family history of a parent and / or sibling suffering from CHD, many spontaneous miscarriages, exposure to teratogenic medications or radiation [8]. Regarding maternal risks, maternal age (over 35years old), viral infections during pregnancy, having a balanced diet rich in iron, calcium, vitamins and folic acid and preventing pregestational diabetes. Others, include in-vitro fertilized fetuses, multiple fetuses and increased nuchal translucency (NT) [9]. Echocardiography (echo-2D) for prenatal diagnosis of CHD has been uses successfully, since the 1980 's. Recent studies prove efficiency in early detecting CHD by echo-2D delivered in the end of the $1^{\text {st }}$ and beginning of $2^{\text {nd }}$ trimester [10]. Recently, a combination of biochemical tests and imaging indexes during $11-13^{\text {th }}$ weeks of gestation by combining increase NT, doppler flow pattern in the ductus venosus with maternal serum pregnancy-associated plasma protein-A (PAPP-A), and free beta-human chorionic gonadotropin (freehCG), is successfully used. This test, provides a high prediction of chromosomal abnormalities that are very common related to CHD as Down's syndrome [11]. It increases the detection rate to $96 \%$ with a $2.6 \%$ false-positive rate $[2,12]$. Unfortunately to all above measures and costs, most causes leading to CHDs remain still unexplained and many cases are prenatally undetected, mostly in the less privileged countries
[2,3,7-9]. Resent breakthrough in early postnatal detection for critical-CHD (c-CHD) in term neonates is achieved by using pox. In this subcategory of CHD, early diagnosis and interventional/ surgical treatment must be offered in the first month of life to avoid serious morbidity or death. This sub-group consists of complex cyanotic defects, systemic and pulmonary ductus arteriosus (DA) depending circulations and the severe LV outflow tract obstruction lesions. This screening test emerged in 2005, by Anne de Wahl Granelli et al. [12] after measuring the saturation of oxygen $\left(\mathrm{SpO}_{2}\right)$ in 40.000 healthy newborns and comparing the values to newborns with c-CHD. Additionally, showed that two out of three infants with c-CHD were missed by routine physical examination alone [12]. A systematic review and meta-analysis of pox screening for c-CHD in newborns, which included 13 studies with 229,421 newborns, proved the efficacy of pox.

Sensitivity was $76.5 \%$ and specificity was $99.9 \%$ for the detection of c-CHD, with an average falsepositive rate of $0.14 \%$

In term neonates, using an $\mathrm{SpO}_{2}$ value $>95 \%$ after the first day of life, pox has been proven a successful screening test in early detection of cyanotic and c-CHD as: tetralogy of Fallot, dtransposition of the great arteries, total anomalous pulmonary venous drainage, tricuspid atresia, pulmonary valve atresia with intact interventricular septum, hypoplastic left heart syndrome, common truncus arteriosus, double outlet right ventricle and Ebstein anomaly. These lesions, represent at least $25 \%$ of all CHD. Although, associated with cyanosis, can be clinically undetected during the early neonatal age, due to the "cyanotic clinical blind spot" that appears as hemoglobin $>13.5 \mathrm{gr} / \mathrm{dL}$ at birth [12-20]. Based on the existing low peripheral perfusion in left heart obstructive conditions, as severe aortic valve stenosis, coarctation of the aorta and interrupted aortic arch conditions, resent studies show that technological advanced devises using perfusion index, can improve detection rates of not cyanotic forms of $\mathrm{c}$ CHD [15,17].

\section{Discussion}

Any prevention method used in clinical practice, ought to deliver specific qualities. It must be 
reliable in detecting a common and/or even lethal disease with a high level of sensitivity and specificity. It needs to be as less as invasive, easy to apply and inexpensive around the globe16. It is obvious that as more preventive methods are used, the less accurate they are. Therefore, a combination of them is needed. CHD's express these circumstances [2,8-13]. The 2007-2009 World Society for Pediatric Heart Surgery Manpower Survey noted that about $75 \%$ of the world's population have no access to cardiac surgery, and that the distribution of cardiac surgeons was very unbalanced worldwide [3,7]. So, any prevention/ early detection measure is better than none. Pox used as an early detection/screening test after 72 hours from birth ideally or as late as possible after 24 hours-for the early discharged neonates-carries all the benefits of a screening test, mentioned above [2,12-15,17]. With an exception of the "home deliveries", in all others, a universally offered physical examination postnatally, just before discharge from a maternity facility has been the only detection method for CHD. This has been found to be insufficient to detect even c-CHD. Nowadays, as the "color" index of the Apgar score has been replaced with a pox measurement, these, have been established in every day practice [18]. Using pox in additional measurements -after the DA has physiologically closed (day 2 of life in term babies)- will detect all the cyanotic babies. Those that fail a hyperoxia test and proved not to have early sepsis onset or acute respiratory disease, will be babies suffering from c-CHD [2,15,17-19]. This has been also proven by Zhao et al. [17] in a recent very large study. They also stated that addition to pox, clinical assessment improves sensitivity for detection of c-CHD from $77 \cdot 4 \%$ to $93 \cdot 2 \%$, when used in simultaneous pre and post DA measurements, after 72 hours of birth [17]. With the technological advances in pulse oximetry devises and improving the perfusion index we will be probably able to detect easily all the noncyanotic c-CHD during the first week of life of the term neonate $[1,17]$. Furthermore, the recent study of the Italian Society of Neonatology, verifies these findings and suggests the use of the perfusion index -available in new generation devices-to increase the reliability of measurements and improve detection of non-cyanotic c-CHD's
[20].

\section{Conclusion}

Since the "Holy Grail" of CHD prevention/early detection has not been still found and patient numbers in the less privilege countries, suffering from CHD are vastly increasing, a prevention/ early detection strategy is needed. Additional to avoiding the teratogenic elements or conditions leading to CHD's, promoting a healthy pregnancy and offering under indications fetal Cardiac consultations, pox combined with clinical assessment is a feasible and reliable postnatal early detection screening test. This simple, low cost, noninvasive and accurate method must be used as a worldwide screening test for c-CHD Figure 1. Although adopted in many healthcare facilities around the world, we lack a consensus in its use. To achieve this, specific guideline is needed to unify its use.

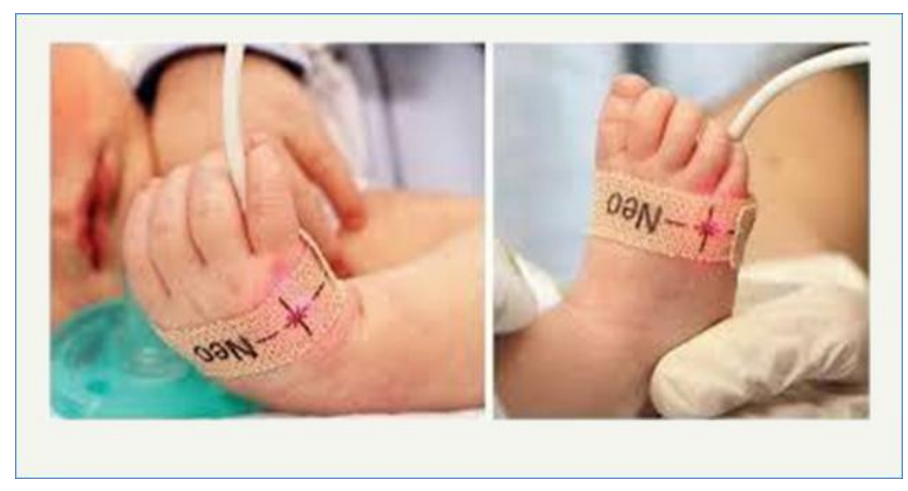

Figure 1: Pulse oximetry for CHD screening test.

Financial source: Did not use financial resources.

Conflict of interest: None.

\section{REFERENCES}

1. Schiefsk M (2005) Hippocrates on Ancient Medicine. Brill Academic Publishers

2. Rudolf AM (2009) Congenital Diseases of the HeartClinical \& Physiological Considerations 3rd (Edn.), Wiley- Blackwell.

3. Boyd PA, Devigan C, Garne E, Khoshnood B, Loane $M$, et al. (2005) Prenatal Screening Policies in Europe. EUROCAT Special Report, Ulster.

4. Knowles R, Griebsch I, Dezateux C, Brown J, Bull C, et al. (2005) Newborn screening for congenital heart defects: a systematic review and cost 
effectiveness analysis. Health Technol. Assess 9(44): 1-152.

5. (2013) Jekel's Epidemiology, Biostatistics, Preventive Medicine, and Public Health Publisher 4th (Edn.), Saunders.

6. Mitchell SC, Korones SB, Berendes HW (1971) Congenital heart disease in 56,109 births. Incidence and natural history. Circulation 43(3): 323-332.

7. Wren C (2012) The epidemiology of cardiovascular malformations. In: Moller JH, Hoffman JIE, Benson DW, van Hare GF, Wren C (Eds.), Pediatric Cardiovascular Medicine. Wiley-Blackwell, Oxford, England, pp: 268-275.

8. Hoffman JIE (2013) The global burden of congenital heart disease Cardiovasc. Cardiovasc J Afr 24(4): 141-145.

9. Petropoulos AC, Moschovi M, Xudiyeva A, Qarayev F, Isayev I (2017) Late Coarctation Presenters Suffer Chronic Hypertension Resisting to Medicine Treatment. Peertechz J Pediatr Ther 3(1): 001-008.

10. (2012) Ministry of Health of the People's Republic of China. National birth defects control and prevention report.

11. List_of_sovereign_states_and_dependent_territories _b y_fertility_rate

12. Marino BS, Lipkin PH, Newburger JW, Peacock G, Gerdes M, et al. (2012) Neurodevelopmental outcomes in children with congenital heart disease: evaluation and management: a scientific statement from the American Heart Association. Circulation 126(9): 1143-1172.

13. Bernier PL, Stefanescu A, Samoukovic G, Tchervenkov CI (2010) The challenge of congenital heart disease worldwide: epidemiologic and demographic facts. Sem thorac cardiovasc surg. Pediatr Card Surg A 13: 26-34.

14. Brent RL (2004) Environmental causes of human congenital malformations: the pediatrician's role in dealing with these complex clinical problems caused by a multiplicity of environmental and genetic factors. Pediatrics 113(4S): 957-968.

15. Petropoulos AC, Xudiyeva A, Ismaylova M (2016) Congenital Heart Disease and Maternal Diabetes Mellitus. International Journal of Diabetes \& Clinical Diagnosis 3: 118 .

16. Bader RS, Hornberger LK, Huhta JC (2008) The Perinatal cardiology 1st (Edn.), Handbook, Elsevier Inc, Mosby.

17. Midan MF, Alsheemy RI, Eid SM, Salam MEA (2016) Efficacy of fetal echocardiography in prenatal diagnosis of congenital heart diseases. Int J Reprod Contracept Obstet Gynecol 5(5): 1553-1557.

18. Kleiman CS, Hoddins JC, Jaffee CC, Lynch DC, Talner NS (1980) Echocardiography studies of the human fetus: prenatal diagnosis of congenital heart disease and cardiac dysrhythmias. Pediatrics 65(6): 1059-1067.

19. Simpson JM (2009) Impact of fetal echocardiography. Ann Pediatr Cardiol 2(1): 41-50.
20. Carvalho JS, Moscoso G, Tekay A, Campbell S, Thilaganathan B, et al. (2004) Clinical impact of first and early second trimester fetal echocardiography on high risk pregnancies, Heart 90(8): 921-926.

21. Maiz N, Nicolaides KH (2010) Ductus Venosus in the First Trimester: Contribution to Screening of Chromosomal, Cardiac Defects and Monochorionic Twin Complications, Fetal Diagn Ther 28(2): 65-71.

22. Wapner R, Thom E, Simpson JL, Pergament E, Silver R, et al. (2003) First-Trimester Screening for Trisomy's 21 and 18, N Engl. J Med 349(15): 1405 1413.

23. Rocha LA, Araujo Júnior E, Machado Nardozz LM, Moron AF (2013) Screening of fetal congenital heart disease: the challenge continues, Rev Bras Cir Cardiovasc 28(3): 5-7.

24. (2006) International Society of Ultrasound in Obstetrics \& Gynecology. Cardiac screening

25. examination of the fetus: guidelines for performing the 'basic' and 'extended basic' cardiac scan. Ultrasound Obstet Gynecol 27(1): 107-113.

26. Quartermain MD, Pasquali SK, Hill KD, Goldberg DJ, Huhta JC, et al. (2015) Variation in Prenatal Diagnosis of Congenital Heart Disease in Infants, Pediatrics 136(2): e378-385.

27. (2016) Textbook of Neonatal Resuscitation Program (7th edition) Update; AAP.

28. Qu-ming Zhao, Xiao-jing Ma, Xiao-ling Ge, Fang Liu, Wei-li Yan, et al. (2014) Pulse oximetry with clinical assessment to screen for congenital heart disease in neonates in China:a prospective study, The Lancet 384(9945): 747-754.

29. de Wahl Granelli A, Wennergren M, Sandberg K, Mellander M, Bejlum C, et al. (2009) Impact of pulse oximetry screening on the detection of duct dependent congenital heart disease: a Swedish prospective screening study in 39,821 newborns. BMJ 338: a3037. 